\title{
Effect of Different Types of Milk on Shelf Life and Microbial Quality of Rabri
}

\author{
Anoop Singh Chauhan*, S. P. Singh, K. V. Singh and S. J. Singh \\ Department of Animal Husbandry \& Dairying, C. S. Azad University of Agriculture \& Technology, Kanpur, \\ U.P- 208002, India; aschauhan8366@gmail.com
}

\begin{abstract}
Study was conducted to evaluate the effect of various four storage periods ( 0 day, 5 days, 10 days and 15 days) and four different types of milk (cow milk, buffalo milk, combined milk and skim milk) used for the preparation of Rabri. These samples were stored at $5^{\circ} \mathrm{C}$, and evaluated the three species of microorganisms (standard plate count X $10^{5} \mathrm{Cfu} / \mathrm{g}$, coliform count X $10^{2} \mathrm{Cfu} / \mathrm{g}$ and yeast \& mould count X $10^{2} \mathrm{Cfu} / \mathrm{g}$ ) which were noticed during storage. This evaluation process replicated thrice. The various storage periods and four different types of milk used for the preparation of Rabri, affected significantly at $0.1 \%$ level of significance but the microbial populations were not affected significantly at $5 \%$ level of significance. The interaction between storage periods and milk, storage periods and microbes and milk and microbes significantly affected at the level of $0.1 \%$. The overall interaction among storage period, milk and microbes found to be non-significant effect at $5 \%$ level of significance. The intensity of contamination was depending on types of milk and days of storage periods. The presence of total solids plays role in growth of microbes such as least number of cfu/g present in sample prepared by buffalo milk, whereas highest noticed in skim milk. The role of storage periods, as Rabri samples got old the intensity of contamination and growth of microbes increased. Least number of cfu /g noticed at 0 day and highest at 15 days of storage. The significant increase in SPC was observed after 10 to 15 days, but non-significant growth of coliform count and yeast mould count was noticed between 0 to 10 days of storage but growth was observed after 10 days of storage. It was recommended that the best quality of Rabri can be obtained by using buffalo milk at current day of preparation, the least microbial load was found at 0 to 10 days of storage but it would be remain consumable up to 15 days when it stored at $5^{\circ} \mathrm{C}$.
\end{abstract}

Keywords: Microorganism and Quality, Milk, Rabri, Storage Periods

\section{Introduction}

Rabri is a heat desiccated thickened milk product with light caramel colour and having pleasant sweet flavour. It is essentially clotted cream, skimmed off from slowly evaporating milk. It is very popular traditional Indian dairy product, especially in the northern and eastern regions of India and synonymous of clotted cream. Rabri is a specialized product of halwais. Thin layers of clotted cream formed on the surface of milk are collected to the sides with a wooden spatula. The layers of cream clotted on the edge of pan are placed one over the other. This process is continued until $1 / 5$ th of original milk is left. Sugar $6 \%$ by weight of original milk is added to the concentrated milk. The clotted cream called Malai is scrapped off from the edge of pan and immersed in thick sweetened milk ${ }^{1}$. Rabri prepared by traditional method is unhygienic, non-uniform in quality, has low keeping quality and involves labour and energy intensive method of production. Consequently the cost of this product is usually very high. Rabri are produced on tiny scale by traditional practices without much consideration given to quality of milk and final product ${ }^{2}$. The production is limited to small batches of 5 to 10 litres of milk. For large scale

${ }^{*}$ Author for correspondence 
production of Rabri, vacuum concentration of milk followed by blending it with required quantities of sugar and malai was attempted. Optimization of the process parameters of three stages SSHE for continuous Rabri production, process was developed to manufacture Rabri by integrating Scraped Surface Heat Exchanger (SSHE) with Conical Process Vat (CPV). SSHE is most suitable for handling viscous product with or without particles, products that tend to foul the heat transfer surface ${ }^{3}$. Milk and milk products have high nutritive value but are most prone to contamination with different types of microorganisms due to unhygienic conditions and improper handling and storage. The consumption of unhygienic contaminated food leads to food borne diseases which cause considerable morbidity and mortality. In India people use many types of milk products including Rabri, partially desiccated milk which is traditionally used in preparation of various sweets, vegetable curries etc. In tropical countries like India dairy products have been found to be responsible for many outbreaks of gastrointestinal infections. Dairy products prepared under unhygienic conditions pose a great threat to the health of the consumer. The high nutritive value and high water activity (0.96) of Rabri is conducive to growth of bacteria. Microbial contamination produces undesirable effects like change in colour, odour, taste and texture of the product, besides contamination of products with pathogenic bacteria can result in outbreaks of gastrointestinal infections.

\section{Materials and Methods}

There were four storage periods ( 0 day, 5 days, 10 days and 15 days) and four types of milk (cow, buffalo, combined and skim milk) used for the preparation of Rabri these samples were stored at $5^{\circ} \mathrm{C}$, and evaluate three species of microorganism (standard plate count X $10^{5} \mathrm{Cfu} / \mathrm{g}$, coliform count X $10^{2} \mathrm{Cfu} / \mathrm{g}$ and yeast \& mould count X $10^{2}$ $\mathrm{Cfu} / \mathrm{g}$ ) which were contaminated during storage. This evaluation process replicated three times. Technological process flows as lines of 'annual report' NDRI, KARNAL as fallowed as suggested by Verma, D., ${ }^{4}$. The pure plate method of BIS was followed to estimate the standard plate count (SPC), for this readymade plate count agar media of Himedia Laboratories, Mumbai- 400086. Violet Red Bile Agar (VRBA) used to estimate the coliform count and Potato Dextrose Agar (PDA) used for yeast \& mould count. The obtained data during the study were subjected for analysis of variance (ANOVA) as described by Snedecor and Cochran.

\section{Manufacture Procedure}

Rabri was prepared in the laboratory by the method of Verma ${ }^{4}$. Rabri was normally prepared by heating 3-4 kg of milk in a Karahi over on open fire to simmering temperature $\left(85-90^{\circ} \mathrm{C}\right)$ and then maintaining the temperature by controlled heating. The milk was neither stirred nor allowed to boil. The surface of the milk could be gently fanned to help the process of skin formation. A piece of this skin about 3-4 cm. square was continuously broken with a thick wooden stick (or bamboo/can splints) and moved to the cooler parts of the Karahi. These operations require considerable skill and constant attention. Simultaneously, as slow evaporation reduces the milk to about one fifth of its original volume, good quality ground sugar by weight basis of the original milk was added to the milk concentrate and dissolved in it. The layers of skin collected on the Karahi surface and then immersed in the mixer and the finished product obtained by gently heating the whole mass for another brief period.

\section{Result and Discussion}

The results of microbiological evaluation of Rabri are depicted in Tables 1 and 2. The obtained data of this work showed that the least number (2.389) of microbial colony forming units/g $(\mathrm{cfu} / \mathrm{g})$ were noted at 0 day and at $5^{\text {th }}$ day product contained $3.750 \mathrm{CFU} / \mathrm{g}$ and at $10^{\text {th }}$ day $5.528 \mathrm{CFU} / \mathrm{g}$ found in the rabri whereas highest number (7.250) of CFU/g noticed at $15^{\text {th }}$ days of storage. Effect of various storage periods in respect of microbial content found to be significant at the level $0.1 \%$ level of significance 5 . The product as gone older the intensity of microbial contamination increases and vice versa. The effects of various type of milk on the number of microorganism found in the Rabri were found to be significant at the level of $0.1 \%$ level of significance. Lowest population of microorganism (3.750) noticed in Rabri samples which were prepared by buffalo milk. The cow milk and the combined milk used in preparation of samples contained 4.806 and $4.528 \mathrm{CFU} / \mathrm{g}$, respectively. Whereas highest population of microorganism (5.833) were found in Rabri prepared by from skim milk. Here it was noticed that highest percentage of total solids retorted the growth of 
Table 1. Analysis of variance table

\begin{tabular}{lccccc}
\hline Source & D.F. & S.S. & M.S. & F-cal & CD \\
\hline Storage periods (A) & 3 & 483.4 & 161.14 & $152.66^{* * *}$ & 0.481 \\
Milk (B) & 3 & 80.08 & 26.69 & $25.29^{* * *}$ & 0.481 \\
Factor A X B & 9 & 6.28 & 0.70 & $0.66^{* * *}$ & 0.962 \\
Microbes (C) & 2 & 3787.17 & 1893.58 & $1793.92 \mathrm{NS}$ & $\mathrm{NS}$ \\
Factor A X C & 6 & 249.78 & 41.63 & $39.44^{* * *}$ & 0.833 \\
Factor B X C & 6 & 21.11 & 3.52 & $3.33^{* * *}$ & 0.833 \\
Factor AxBxC & 18 & 21.28 & 1.18 & $1.12 \mathrm{NS}$ & $\mathrm{NS}$ \\
Error & 96 & 101.33 & 1.06 & & \\
Total & 143 & 4750.44 & & & \\
\hline
\end{tabular}

${ }^{* * *}$ significant at $0.1 \%$ level of significance

** significant at $1 \%$ level of significance

* significant at $5 \%$ level of significance

N. S. - non-significant at $5 \%$ level of significance

CD- critical difference

Table 2. Mean score of microbial content

\begin{tabular}{llccc}
\hline Factors & Milk & SPC & $\begin{array}{c}\text { Coliform } \\
\text { count }\end{array}$ & $\begin{array}{c}\text { Yeast \& } \\
\text { mould } \\
\text { count }\end{array}$ \\
\hline 0 Day & Cow milk & 8.000 & 0.000 & 0.000 \\
& Buffalo milk & 4.667 & 0.000 & 0.000 \\
& Combined milk & 6.667 & 0.000 & 0.000 \\
& Skim milk & 9.333 & 0.000 & 0.000 \\
5 Days & Cow milk & 11.000 & 0.000 & 0.000 \\
& Buffalo milk & 8.333 & 0.000 & 0.000 \\
& Combined milk & 10.333 & 0.000 & 0.000 \\
& Skim milk & 12.000 & 2.000 & 1.333 \\
& Cow milk & 13.667 & 2.000 & 1.333 \\
& Buffalo milk & 11.667 & 1.333 & 0.000 \\
& Combined milk & 13.000 & 2.333 & 1.667 \\
& Skim milk & 14.333 & 3.000 & 2.000 \\
& Cow milk & 17.667 & 2.000 & 2.000 \\
& Buffalo milk & 16.000 & 1.000 & 2.000 \\
& Combined milk & 17.000 & 2.000 & 1.333 \\
& Skim milk & 18.000 & 4.667 & 3.333 \\
\hline \multirow{7}{*}{ Days } & & &
\end{tabular}

microorganism in the product but less total solids provides the favourable condition for growth of microorganism. The effect of various species of microorganism found to be non-significant at the level of 5\% level of significance. It was observed that highest number of microorganism found as under the standard plate count $\left(11.979 \times 10^{5} \mathrm{CFU} / \mathrm{g}\right)$, whereas the mean score of coliform count and yeast \& mould count were found as $1.271 \mathrm{X}$
$10^{2} \mathrm{CFU} / \mathrm{g}$ and $0.938 \times 10^{5} \mathrm{CFU} / \mathrm{g}$, respectively. This data shows that most of the samples free from the contamination of coliform count and yeast \& mould count but total plate count found in all samples. The interaction effect of various storage periods with various type of milk were found to be significant at the level of $0.1 \%$ in context of number of microorganism grown in Rabri. Highest number of microorganism (8.667) were noted in the sample which was prepared by skim milk stored 15 days whereas least number of microbes (2.667) were found in rabri sample which was made by buffalo milk at $0^{\text {th }}$ day. As well as total solids decreases and days of storage increase, the population of microorganism increased gradually. The interaction effect of various storage periods with different types of microorganism were found to be significant at the level of $0.1 \%$ in context of number of microorganism grown in Rabri. Highest number of microorganism (17.167) were noted in standard plate count which was stored for 15 days whereas least number of microbes (0.000) were found of coliform count and yeast \& mould count at $0^{\text {th }}$ day. The interaction effects of various type of milk with different types of microorganism were found to be significant at the level of $0.1 \%$ level of significance in context of number of microorganism grown in Rabri. Highest number of microorganism (13.417) were noted in standard plate count in the Rabri sample which was prepared by skim milk whereas least number of microbes (0.500) were found in rabri which was prepared by buffalo milk contaminated by yeast \& mould count. The overall interaction effect of various storage periods, different types of milk and microorganism which were grown in 
Rabri, was found to be non-significant at the level of $5 \%$ level of significance [5]. The highest number of standard plate count noted in the sample of Rabri which was prepared by skim milk and stored for 15 days whereas least number of standard plate count noted in the combination of product which was prepared by buffalo milk at 0 day. In the concern of coliform count and yeast \& mould count, it was found that most of the combinations were free from contamination by these microbes up to 5 days of storage period but as days of storage periods increases, the number of colonies of these microbes also increases. At 10 and 15 days, the coliform count and yeast $\&$ mould count severely affected to the product samples stored at $5^{\circ} \mathrm{C}^{5}$.

\section{Conclusion}

The findings of study imply that the four various storage periods ( 0 day, 5 days, 10 days and 15 days), four different types of milk (cow, buffalo, combined and skim milk) used for the preparation of Rabri, affected significantly at $0.1 \%$ level of significance but the three various microorganism were not affected significantly. The interaction between storage periods and milk, storage periods and microbes and milk and microbes found to be significant effect at the level of $0.1 \%$. The overall interaction among storage period, milk and microbes found to be non-significant effect at 5\% level of significance. The intensity of contamination was depending on types of milk and days of storage periods. The presence of total solids plays role in growth of microbes such as least number of $\mathrm{cfu} / \mathrm{g}$ present in sample prepared by buffalo milk, whereas highest in skim milk. The role of storage periods, as Rabri samples got old the intensity of contamination and growth of microbes increased. Least number of cfu / g noticed at 0 day and highest at 15 days of storage. The significant increase in SPC was observed after 10 to 15 days, but non-significance growth of coliform count and yeast mould count was noticed between 0 to 10 days of storage but growth was observed after 10 days of storage.

\section{References}

1. Khaskheli M, Jamali A, Arain MA, Nizamani AH, Soomro $\mathrm{AH}$, Arain HH. Chemical and sensory quality of indigenous milk based product 'Rabri'. Pakistan J Nutr. 2008; 7(1):133-36.

2. Dande KG, Gaikwad SM, Shaikh AKM. Utilization of solar energy in dehydration of milk and in the manufacturing of Khoa. African J Food Sci. 2011; 5:814-16.

3. Dodeja AK. Development in traditional dairy products, Lecture compendium of CAS course held at NDRI, Karnal; 2006 Dec 10-30. p. 171-176.

4. Verma D, Dodeja BB, Garg FC. Upgradation of the technology for manufacture of Rabri. Annual Report (2004-05), NDRI, Karnal; 2005. p. 20-21.

5. Singh P, Dixit A, Khan BL. Effect of different levels of fat concentration of milk, sugar levels and storage periods on the microbiological quality of rabri making from Bhadwari buffalo milk. Environment and Ecology. 2009; 27(2):723-24. 